\title{
Reduction of tar, nicotine and carbon monoxide intake in low tar smokers
}

\author{
M A H RUSSELL, ${ }^{1}$ M J JARVIS, ${ }^{1}$ C FEYERABEND, ${ }^{2}$ AND Y SALOOJEE ${ }^{3}$ \\ From the Addiction Research Unit, ${ }^{1}$ Institute of Psychiatry, 101 Denmark Hill, London SE5 8AF; Poisons \\ Unit, ${ }^{2}$ New Cross Hospital, London SE14; and Anaesthetic Research Laboratory, ${ }^{3}$ St Bartholomew's Hospital, \\ London EC1
}

SUMMARY Blood nicotine, cotinine, and carboxyhaemoglobin ( $\mathrm{COHb}$ ) concentrations were measured in 392 smokers ( 255 women and $137 \mathrm{men}$ ) of "middle tar" (17-22mg), "low to middle" (11-16mg), and "low tar" (<11 mg) cigarettes. Since tar intake cannot yet be measured directly, we devised an index to estimate it based on the use of measured levels of an intake marker (eg, blood nicotine) and the ratio of the tar to marker yields of the cigarettes. This approach was validated by its ability to enhance the prediction of levels of one marker by use of another. In a practical test, using $\mathrm{COHb}$ and the $\mathrm{CO} /$ nicotine yield ratio of the cigarettes, the mean blood nicotine concentration of the low tar smokers was predicted to be $31 \cdot 9 \mathrm{ng} / \mathrm{ml}$ compared with the measured mean of $31 \cdot 8 \mathrm{ng} / \mathrm{ml}$. Our main findings were that despite substantial compensatory increases in inhalation, the low tar smokers took in about $25 \%$ less tar, about $15 \%$ less nicotine, and about $10 \%$ less carbon monoxide than smokers of middle and low to middle tar cigarettes. These results indicate that low tar cigarettes of the type available in Britain since the late 1970s are likely to prove less harmful than other brands. Monitoring of smoke intakes could supplement epidemiological approaches and provide earlier evidence of whether changing cigarette designs lead to any significant dosage reduction that could affect the risk of disease.

For more than a decade many countries have had policies for reducing the tar and nicotine yields of cigarettes. Such policies are based on the assumption that the amounts taken in by smokers will also be reduced, so lowering their risk of developing smoking related diseases. It has become apparent, however, that much of the potential health benefit is undermined by the tendency of smokers who smoke lower yielding cigarettes to smoke them more intensively. Several studies have shown that despite large reductions in the machine smoked yields of their cigarettes (up to $40 \%$ ) smokers who have chosen to smoke a lower yielding brand have blood nicotine, ${ }^{12}$ cotinine ${ }^{3}$ and $\mathrm{COHb}^{14}$ concentrations similar to or only slightly lower than those of other smokers.

In this paper we compare blood nicotine, cotinine, and $\mathrm{COHb}$ levels in smokers of "low tar" (LT) cigarettes $(<10.5 \mathrm{mg}$ tar per cigarette) with those of "low to middle" and "middle tar" smokers to see the extent to which lower yields are associated with lower intakes. Although tar intake is of particular concern, no direct measures are yet available. We have devised and validated an index of tar intake based on the blood levels of a marker such as nicotine or $\mathrm{CO}$ and the tar/nicotine or tar/CO yield ratios of the cigarettes. We use this index to estimate the tar intake of LT smokers compared with smokers of other brands.

\section{Subjects and methods}

The study population consisted of cigarette smokers who attended the Maudsley Hospital smokers' clinic during 1978-81. We excluded those who smoked cigars or hand rolled cigarettes and six subjects who smoked cigarettes in the "middle to high" tar category $(23-28 \mathrm{mg} / \mathrm{cig})$. The number of subjects after these exclusions was 255 women and 137 men.

All subjects attended in the afternoon, having been instructed to smoke their usual brand in their usual way. On arrival they were asked to smoke one of their cigarettes, and a venous blood sample was taken two minutes after they had finished it. Plasma nicotine and cotinine concentrations were measured by gas chromatography ${ }^{56}$ and $\mathrm{CO}$ intake was measured using an IL $182 \mathrm{CO}$-oximeter or an Ecolyzer. ${ }^{7}$ The tar, nicotine, and $\mathrm{CO}$ yields of the cigarettes were 
obtained from the tables published by the Health Departments of the United Kingdom.

An index of tar intake was derived from the measured intake of a marker and the ratio of the tar to marker yields of the cigarette. For example, the index of tar intake using plasma nicotine concentration as a marker was derived as follows:

TI $\left(\right.$ Nic) $=$ Plasma nicotine $\times \frac{\text { Tar yield of cigarette }}{\text { Nicotine yield of cigarette }}$

$=$ Plasma nicotine $\times \mathrm{T} / \mathrm{N}$ yield ratio

Such an index assumes that the intake of different smoke components relative to one another is in proportion to their concentrations in the smoke. Since we measured more than one marker it was possible to test the validity of this approach by its ability to predict the levels of one marker from another better than the simple correlation between the two.

\section{Results}

Table 1 gives the details of the cigarette consumption and intake measures of men and women according to the tar group of their cigarettes. On average, the women were two years younger than the men, and more of them were LT smokers $\left(43 v 31 \%, \chi^{2}=5 \cdot 0\right.$, $\mathrm{p}<0 \cdot 05)$. Although daily cigarette consumption was slightly lower in the women, the number of cigarettes smoked before the blood test on the day they were seen was similar in men and women. There were no statistically significant sex differences in any of the three intake measures (table 1).

There was no relation between tar group and cigarette consumption. In particular, there was no tendency for LT smokers to smoke more cigarettes. However, in both men and women, the blood levels of all three intake measures were significantly lower in the LT smokers. The average levels in the men and women combined for middle, low to middle, and LT smokers respectively were: $38.8,37.0$, and $31 \cdot 8 \mathrm{ng} / \mathrm{ml}$ nicotine; 367,416 , and $333 \mathrm{ng} / \mathrm{ml}$ cotinine; and $7 \cdot 8,8 \cdot 0$, and $7 \cdot 1 \% \mathrm{COHb}$. In no case did the low to middle tar group differ significantly from the middle tar group, whereas in each case the levels in the LT smokers were significantly lower than in the other two groups.

RELATION OF CIGARETTE YIELDS TO CONCENTRATIONS IN BLOOD

In the figure the individual values for each marker are plotted against the corresponding standard machine smoked yields of the cigarettes smoked. The data for men and women were combined because their patterns were similar and the regression lines for men and women did not differ significantly. The pattern was also similar for the three intake measures, showing wide variation between subjects but little relation to cigarette yields. The correlations between cigarette yields and blood concentrations were statistically significant but low. The cigarette nicotine yield accounted for only $6.8 \%$ of the variance in blood nicotine and $1.7 \%$ of the variance in blood cotinine. Likewise, CO yield accounted for only $6 \cdot 3 \%$ of the variation in $\mathrm{COHb}$.

NICOTINE, CO, AND TAR INTAKE

Table 2 compares the intakes of LT and non-LT smokers. The average blood nicotine and cotinine

Table 1 Cigarette consumption and intake measures of men and women smokers of different types of cigarette

\begin{tabular}{|c|c|c|c|c|c|c|c|c|c|c|}
\hline & \multicolumn{3}{|l|}{ Men } & \multicolumn{3}{|l|}{ Women } & \multicolumn{2}{|l|}{ Totals } & \multicolumn{2}{|c|}{$\begin{array}{l}\text { Statistical significance } \\
\text { of differences }\end{array}$} \\
\hline & $\begin{array}{l}\text { Middle } \\
\text { tar } \\
(n=70)\end{array}$ & $\begin{array}{l}\text { Low to } \\
\text { middle } \\
\text { tar } \\
(n=25)\end{array}$ & $\begin{array}{l}\text { Low } \\
\operatorname{tar} \\
(n=42)\end{array}$ & $\begin{array}{l}\text { Middle } \\
\text { tar } \\
(n=109)\end{array}$ & $\begin{array}{l}\text { Low to } \\
\text { middle } \\
\text { tar } \\
(n=37)\end{array}$ & $\begin{array}{l}\text { Low } \\
\text { tar } \\
(n=109)\end{array}$ & $\begin{array}{l}\text { Men } \\
(n=137)\end{array}$ & $\begin{array}{l}\text { Women } \\
(n=255)\end{array}$ & $\begin{array}{l}\text { Between tar } \\
\text { groups }\end{array}$ & Between sexes \\
\hline $\begin{array}{l}\text { Age of subjects (yr) } \\
\text { Yields of cigarettes (mg): }\end{array}$ & $38 \cdot 8$ & $40 \cdot 7$ & $42 \cdot 8$ & $37 \cdot 0$ & $38 \cdot 5$ & $39 \cdot 8$ & $40 \cdot 4$ & $38 \cdot 4$ & $F=3.5, p<0.05$ & $F=3.9, p<0.05$ \\
\hline Tar & $17 \cdot 9$ & $15 \cdot 3$ & $9 \cdot 1$ & $18 \cdot 1$ & $15 \cdot 1$ & $9 \cdot 2$ & $14 \cdot 8$ & 13.9 & & \\
\hline Nicotine & $1 \cdot 48$ & $1 \cdot 23$ & 0.84 & 1.47 & $1 \cdot 28$ & 0.87 & $1 \cdot 24$ & $1 \cdot 18$ & $F>100, p<0.001$ & $\mathrm{~F}=0.9, \mathrm{NS}$ \\
\hline $\begin{array}{l}\text { Carbon monoxide } \\
\text { Cigarette consumption: }\end{array}$ & $17 \cdot 1$ & $15 \cdot 0$ & 10.9 & $17 \cdot 4$ & $14 \cdot 4$ & $11 \cdot 0$ & $14 \cdot 8$ & $14 \cdot 2$ & $F>100, p<0.001$ & $\mathrm{~F}=0 \cdot 3, \mathrm{NS}$ \\
\hline $\begin{array}{l}\text { Usual number per day } \\
\text { Number on day } \\
\text { Intake measures: }\end{array}$ & $\begin{array}{l}32 \cdot 8 \\
14 \cdot 6\end{array}$ & $\begin{array}{l}29 \cdot 1 \\
14 \cdot 0\end{array}$ & $\begin{array}{l}31 \cdot 9 \\
15 \cdot 5\end{array}$ & $\begin{array}{l}28 \cdot 9 \\
13 \cdot 7\end{array}$ & $\begin{array}{l}32 \cdot 4 \\
16 \cdot 3\end{array}$ & $\begin{array}{l}28 \cdot 0 \\
13 \cdot 0\end{array}$ & $\begin{array}{l}31 \cdot 8 \\
14 \cdot 8\end{array}$ & $\begin{array}{l}29 \cdot 0 \\
13 \cdot 8\end{array}$ & $\begin{array}{l}F=0 \cdot 6, \mathrm{NS} \\
F=0 \cdot 9, \mathrm{NS}\end{array}$ & $\begin{array}{l}F=4.9, p<0.05 \\
F=1 \cdot 3, \mathrm{NS}\end{array}$ \\
\hline $\begin{array}{l}\text { Plasma nicotine }(\mathrm{ng} / \mathrm{ml}) \\
\text { Plasma cotinine }(\mathrm{ng} / \mathrm{ml}) \\
\text { COHb }\left(\%_{1}\right)\end{array}$ & $\begin{array}{c}38 \cdot 3 \\
357 \\
7 \cdot 6\end{array}$ & $\begin{array}{c}37 \cdot 9 \\
438 \\
8 \cdot 4\end{array}$ & $\begin{array}{c}34 \cdot 8 \\
382 \\
7 \cdot 4\end{array}$ & $\begin{array}{c}39 \cdot 1 \\
370 \\
7 \cdot 9\end{array}$ & $\begin{array}{c}36 \cdot 4 \\
403 \\
7 \cdot 8\end{array}$ & $\begin{array}{c}30 \cdot 7 \\
327 \\
6 \cdot 9\end{array}$ & $\begin{array}{c}37 \cdot 2 \\
382 \\
7 \cdot 7\end{array}$ & $\begin{array}{c}35 \cdot 1 \\
354 \\
7 \cdot 4\end{array}$ & $\begin{array}{l}F=10.7, p<0.001 \\
F=3.0, p=0.051 \\
F=3 \cdot 7, p<0.05\end{array}$ & $\begin{array}{l}F=0 \cdot 8, N S \\
F=0 \cdot 3, N S \\
F=0 \cdot 2, N S\end{array}$ \\
\hline
\end{tabular}

Note: All values are the means for the smokers in each tar group. The tar groups of their cigarettes were categorised according to the published tables issued by the Health Departments of the United Kingdom and are as follows: Middle tar (17-22mg/cig), Low to middle tar (11-16mg/cig), and Low tar (0-10mg/cig). The statistical significance of the differences between tar groups and sexes are based on two-way ANOVAs. There were no significant interactions. The plasma cotinine values are based on smaller numbers. The total sample with available plasma cotinine data numbers 241 , but they did not differ from the remainder of the subjects in any of the other measures and variables. 

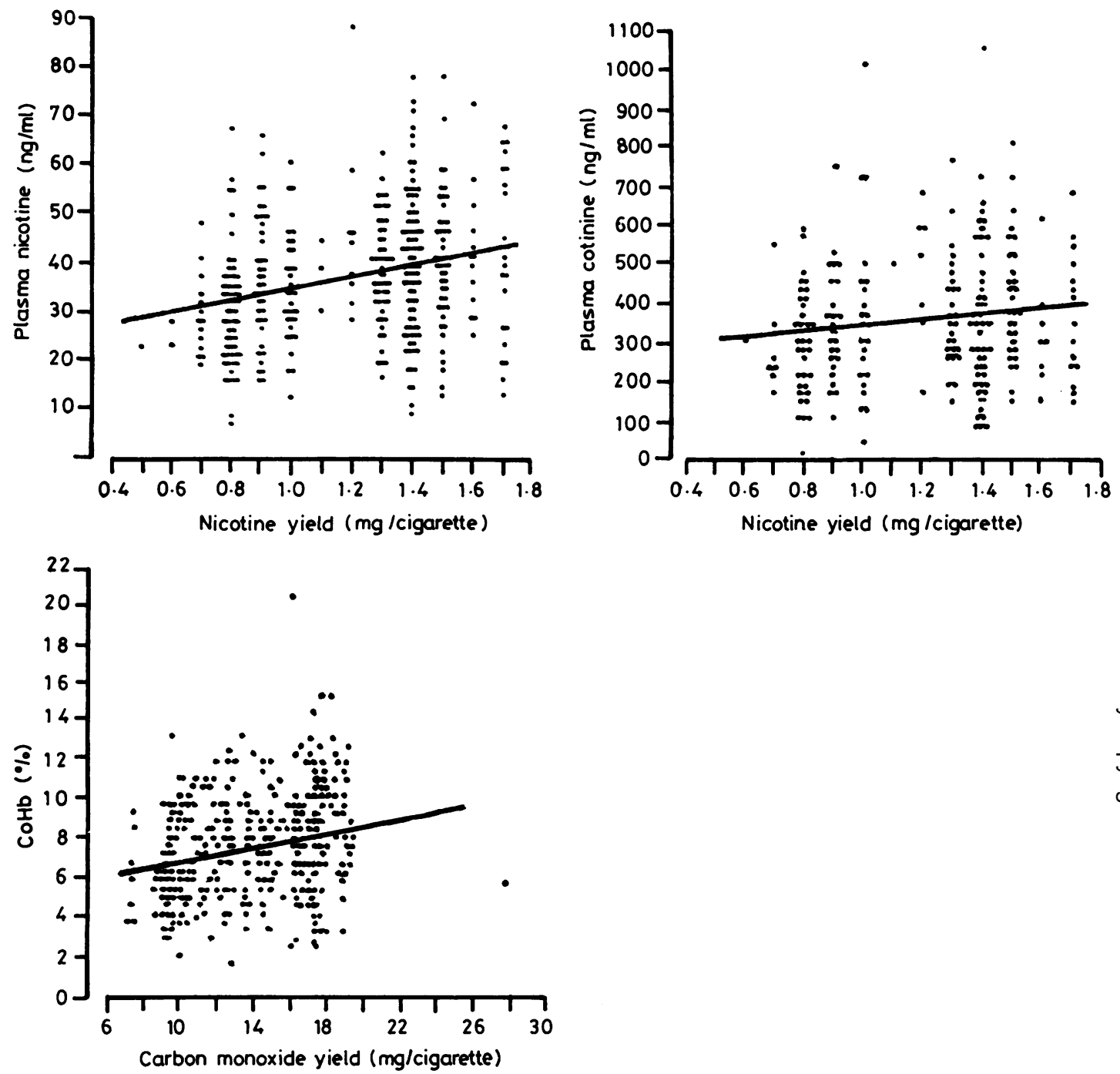

Blood nicotine, cotinine, and $\mathrm{COHb}$ concentrations of individual smokers plotted against the nicotine or carbon monoxide yields of their cigarettes. The linear regression lines are also shown. The regression data were as follows: Blood nicotine $=$ $21 \cdot 8+11 \cdot 7$ nicotine yield, $r=0 \cdot 26, p<0 \cdot 001 ;$ Blood cotinine $=274+71 \cdot 5$ nicotine yield, $r=0 \cdot 13, p<0 \cdot 025 ; C O H b=4 \cdot 7+$ 0.20 carbon monoxide yield, $r=0.25, p<0.001$.

concentrations of LT smokers were respectively $17 \%$ and $12 \%$ lower than in non-LT smokers. The reductions in these two measures of nicotine intake were therefore substantially less than the 39\% reduction in the average nicotine yield of the LT cigarettes, indicating the extent to which the LT smokers were compensating for lower yields by increased inhalation. Similarly, the reduction in CO intake was only $10 \cdot 6 \%$ compared with the $34 \%$ reduction in $\mathrm{CO}$ yield.

Tar intake indices were calculated based on the use of blood nicotine, cotinine, and $\mathrm{COHb}$ as markers. It can be seen in table 2 that there is good agreement between the three estimates. On average the estimated tar intake of the LT smokers was about $25 \%$ less than that of the non-LT smokers. 
Table 2 Average percentage reductions in tar, nicotine, and carbon monoxide intake of low tar smokers in comparison with smokers of higher yield brands.

\begin{tabular}{|c|c|c|c|}
\hline & $\begin{array}{l}\text { Non low tar } \\
\text { smokers } \\
(n=241)\end{array}$ & $\begin{array}{l}\text { Low tar } \\
\text { smokers } \\
(n=151)\end{array}$ & \%,Reduction \\
\hline \multicolumn{4}{|l|}{ Cigarette data: } \\
\hline Tar yield (mg/cig) & $17 \cdot 3$ & $9 \cdot 2$ & $46 \cdot 8$ \\
\hline Nicotine yield (mg/cig) & 1.42 & 0.86 & $39 \cdot 3$ \\
\hline $\mathrm{CO}$ yield (mg/cig) & $16 \cdot 6$ & $11 \cdot 0$ & $34 \cdot 1$ \\
\hline $\mathrm{T} / \mathrm{N}$ ratio & $12 \cdot 3(0 \cdot 08)$ & $10 \cdot 8 \quad(0 \cdot 10)$ & $12 \cdot 1^{* * *}$ \\
\hline $\mathrm{T} / \mathrm{CO}$ ratio & $1.06(0.01)$ & $0.85(0.01)$ & $19 \cdot 8 * * *$ \\
\hline \multicolumn{4}{|l|}{ Intake measures: } \\
\hline Plasma nicotine $(\mathrm{ng} / \mathrm{ml})$ & $38.3 \quad(0.91)$ & $31.8 \quad(0.99)$ & $17 \cdot 0^{* * *}$ \\
\hline Plasma cotinine $(\mathrm{ng} / \mathrm{ml})$ & $379(13.7)$ & $333(16 \cdot 2)$ & $12 \cdot 1^{*}$ \\
\hline $\mathrm{COHb}\left(\%_{1}\right)$ & $7 \cdot 81(0 \cdot 18)$ & $7 \cdot 06(0 \cdot 20)$ & $10 \cdot 6^{* *}$ \\
\hline \multicolumn{4}{|l|}{ Index of tar intake: } \\
\hline TI (Nic) & $469(11 \cdot 2)$ & $341(10 \cdot 4)$ & $27 \cdot 3^{* * *}$ \\
\hline TI (Cot) & $4601(166)$ & $3543(164)$ & $23 \cdot 0^{* * *}$ \\
\hline TI (CO) & $8 \cdot 13(0 \cdot 18)$ & $5.93(0 \cdot 16)$ & $27 \cdot 1^{* * *}$ \\
\hline
\end{tabular}

Note: The plasma cotinine data are based on smaller samples of 146 non low tar smokers and 95 low tar smokers, but these subsamples did not differ from the remainder of the subjects in any of the other measures used. The percentage reduction in $\mathrm{COHb}$ was calculated after subtracting 0.7 to correct for the background level in non-smokers. Standard errors are shown in parentheses. The cigarette yield ratios and indices of tar intake were computed for individual smokers before averaging them to obtain the group means. Statistical significance of differences are based on $t$ tests between non low tar and low tar smokers: ${ }^{* * *} p<0.001,{ }^{* *} p<0.01,{ }^{*} p<0.05$.

VALIDATION OF THE INDEX OF TAR INTAKE It is not possible at present to validate the index of tar intake against a direct measure. However, if a similar index of intake of one marker $(\mathrm{eg}, \mathrm{COHb})$ based on the levels of another marker (eg, blood nicotine) can be shown to enhance the prediction of actual measured levels of the first marker, some validity for the ratio based index of tar intake can reasonably be inferred.

In predicting $\mathrm{COHb}$ from blood nicotine we found that the index of $\mathrm{CO}$ intake (based on the blood nicotine concentration and the $\mathrm{CO} /$ nicotine yield ratio) predicted $\mathrm{COHb}$ substantially and significantly better than blood nicotine concentration on its own (ie, without taking account of the $\mathrm{CO} /$ nicotine yield ratio of the cigarettes). The correlation of the index with $\mathrm{COHb}$ was 0.72 compared with 0.60 between blood nicotine alone and $\mathrm{COHb}$. The index therefore accounted for $52 \%$ of the variation in $\mathrm{COHb}$ compared with $36 \%$ in the case of blood nicotine alone. Likewise, in predicting blood nicotine from $\mathrm{COHb}$, the correlation with the index of nicotine intake (based on $\mathrm{COHb}$ and the nicotine/CO yield ratio) was 0.69 compared with 0.60 between blood nicotine and $\mathrm{COHb}$ alone, a highly significant improvement.

Correlational data of the type described above are concerned with predicting intakes of individual smokers. When comparing large groups or populations, however, much of the variation due to individual differences in intake and differences in half-lives of the markers, etc, will be balanced out. The ability of the index to predict the average levels of smoke components in the LT smokers as a group from the average levels found in the non-LT smokers is illustrated in table 3 . The predictions are close to the measured means, suggesting that the estimated reduction in the tar intake of LT smokers, shown in table 2 , is also likely to be fairly accurate.

\section{Discussion}

Smokers of LT cigarettes had a lower intake of tar, nicotine, and $\mathrm{CO}$ than the smokers of higher yielding brands. On average, their estimated intake of tar was about $25 \%$ lower, their intake of nicotine was about $15 \%$ lower $(17 \%$ and $12 \%$ as measured by blood nicotine and cotinine respectively), and their intake of $\mathrm{CO}$ was about $10 \%$ lower.

These differences are substantially less than the reductions in the standard machine smoked yields of their cigarettes $(47 \%, 39 \%$, and $34 \%$ for tar, nicotine, and $\mathrm{CO}$ yields respectively), and this indicates the extent to which the LT smokers were smoking and inhaling more intensively, presumably to compensate for the lower yields. However, it is clear that despite such compensatory changes in smoking behaviour their intake of the three major smoke components was still lower to a statistically and clinically significant degree.

The results were essentially the same in men and women. There were no significant differences between the sexes in the blood levels of any of the intake measures or in the degree of reduction found in LT smokers.

Table 3 Comparison of the average levels of smoke components measured in low tar smokers with those predicted from the levels in non low tar smokers using the intake index based on a different intake marker

\begin{tabular}{llll}
\hline & $\begin{array}{l}\text { Intake marker } \\
\text { used for } \\
\text { prediction }\end{array}$ & $\begin{array}{l}\text { Predicted } \\
\text { level }\end{array}$ & $\begin{array}{l}\text { Measured } \\
\text { level }\end{array}$ \\
Measure predicted & Blood nicotine & $7 \cdot 0$ & $7 \cdot 1$ \\
COHb $(\%)$ & Blood cotinine & $7 \cdot 3$ & 6.9 \\
COHb $(\%)$ & COHb & 31.9 & $31 \cdot 8$ \\
Blood nicotine $(\mathrm{ng} / \mathrm{ml})$ & COHb & 316 & 333 \\
Blood cotinine $(\mathrm{ng} / \mathrm{ml})$ & COHb &
\end{tabular}

Where blood cotinine concentrations were used as the marker or the measure to be predicted the values are based on fewer subjects.

The formula used for the prediction of $\mathrm{COHb}$ from blood nicotine is shown below. Similar formulae were used to predict the levels of other components using appropriate markers.

Predicted

$\mathrm{COHb}$ in $\mathrm{COHb}$ in Blood nicotine $\times \mathrm{CO} /$ Nicotine yield ratio of $\mathrm{LT}$ smokers $\begin{array}{ll}\mathrm{LT} & \text { non LT } \\ \text { smokers } & \text { smokers }\end{array} \frac{\mathrm{Blood} \text { nicotine } \times \mathrm{CO} / \text { Nicotine yield ratio of non } \mathrm{LT}}{\text { Blo }}$ 
The reductions in nicotine and $\mathrm{CO}$ intake are based on observed levels measured by methods of established reliability. Our findings are consistent with our earlier study ${ }^{1}$ and the more recent report of Ebert $e t a l^{2}$ in showing wide individual variation in blood nicotine concentrations with only a small proportion of the variance accounted for by the nicotine yield of the cigarettes. In our present report, however, we have focussed not on how low the correlation is between nicotine yield of cigarettes and blood nicotine concentrations in smokers but rather on the clinical significance of the slope of the regression lines. In other words, we are less concerned here with how much compensation occurs and more concerned with the extent to which it is incomplete. In this respect we disagree with Benowitz et al, ${ }^{3}$ who conclude that "smokers of low yield cigarettes do not consume less nicotine". Using blood cotinine as their measure of intake, the correlation with yield of cigarette was $0 \cdot 15$, which is similar to our value of $0 \cdot 13$. However, the sample of Benowitz et al was, at 137 , too small to detect a $12-17 \%$ reduction in nicotine intake as was found in our LT smokers. Our findings also differ slightly from those of Wald et al, who measured COHb levels only and concluded that $\mathrm{CO}$ intake was not reduced in smokers of cigarettes with ventilated filters (mainly LT) compared with smokers of cigarettes with unventilated filters (mainly non-LT). ${ }^{4}$ Their results were based not on the measured $\mathrm{COHb}$ levels but on an index which corrected for the previous day's smoking and the reported number of cigarettes smoked on the day and would have relied to some extent on the accuracy of such self-reports.

Our estimate of the reduction in tar intake should be viewed with some caution. The index on which it is based is not a direct measure. Due to lack of reliable evidence we have had to assume that the tar to marker ratios under human smoking conditions are similar to those derived from the standard machine smoked yields or that, if altered, they are altered similarly in LT and non-LT smokers. While it is well known that the yields of all components vary according to the intensity of puffing, it is not clear what happens to the ratios between yields of one component and another. It has been shown that the $\mathrm{T} / \mathrm{N}$ ratio is reduced by increasing the rate of puffing but increased by taking larger puffs. ${ }^{8}$ Fortuitously, this might mean that when both puff rate and puff volume are increased the $\mathrm{T} / \mathrm{N}$ ratio remains fairly constant. The effect on $\mathrm{T} / \mathrm{N}$ ratios of various attempts to replicate human smoking conditions have so far had conflicting results. ${ }^{9-12}$ When more reliable data become available it will be possible to refine our index for estimating tar intake. Meanwhile, the fact that the index, in its present form, has been shown to predict intake better than simple correlation with a marker and the fact that by its use the levels of one marker, predicted from another, were close to the measured levels suggest that our estimate of the reduced tar intake of LT smokers may be fairly accurate.

It is noteworthy that part of the estimated reduction in tar intake reflected the lower ratios of tar to marker yields of LT cigarettes. In other words, tar yields were reduced proportionally more than nicotine and $\mathrm{CO}$ yields. Had the reduction in tar yields been proportionally the same, the reduction in tar intake would have been similar to the $10-15 \%$ reduction in $\mathrm{CO}$ and nicotine intake instead of the $25 \%$ reduction estimated. This points to the importance of considering the ratios of the yields of various smoke components to one another as well as their simple reductions.

Two things should be borne in mind when considering our results. Firstly, our sample consisted of heavy smokers whose average daily consumption of 30 cigarettes per day was almost double that of smokers in the general population. It is possible thap the results would be different in lighter smokers Secondly, the LT smokers were self selected in the sense that they themselves had chosen to smoke a LTo brand. It is possible that if they smoked a higher yield brand their smoke intake would still be lower than that of non-LT smokers so that their lower intake cannot be attributed to the lower yields of theif cigarettes. No prospective study has been published which examines whether natural switching to LT cigarettes is accompanied by a reduction in smoke intake.

Self-selection problems have also bedevilled most of the epidemiological studies of the relative risks of lower yield cigarettes. ${ }^{13}$ The more robust studies based on age-specific secular trends have shown that the lung cancer risk from smoking filter tipped cigarettes of the type now rated as middle tar appears to be lower than that of smoking plain cigarettes of the mid-1950s and before. But they cannot tell us yet about the risk of present-day LT cigarettes and we may have to wait until the year 2000 for this. Indeed, cigarettes and people's smoking habits and choice of cigarettes are now changing so fast that it is difficult to see how epidemiology alone, besides the problems of long delays, could in future come up with any definitive answers. On the other hand, repeated monitoring of smoke intake using several measures could provide us with ready commonsense answers as the years go by and smoking habits and the design of cigarettes change. This could be done as regularly as the Government Chemist now monitors the yields of cigarettes. All the main intake measures can be done by non-invasive methods. 
In conclusion, heavy smokers of present-day LT cigarettes with ventilated filters, despite substantial compensatory increases in inhalation, take in about $25 \%$ less tar, about $15 \%$ less nicotine, and about $10 \%$ less $\mathrm{CO}$ than heavy smokers of higher yielding brands. Part of the reduction in tar intake is due to differences in the ratio of the yields as opposed to simple reductions in yields. We cannot say from the present data whether smokers who have not yet switched to a LT brand would show similar reductions if they did.

We thank the Medical Research Council for financial support and our colleagues Dr Stephen Sutton and Dr Robert West for valuable advice.

\section{References}

${ }^{1}$ Russell MAH, Jarvis M, Iyer R, Feyerabend C. Relation of nicotine yield of cigarettes to blood nicotine concentrations in smokers. Br Med J 1980; 280: 972-6.

${ }^{2}$ Ebert RV, McNabb ME, McCusker KT, Snow SL. JAMA 1983; 250: 2840-2.

${ }^{3}$ Benowitz NL, Hall SM, Herning PJ, Jacob P, Jones RT, Osman AL. Smokers of low-yield cigarettes do not consume less nicotine. $N$ Engl J Med 1983; 309: 139-42.
${ }^{4}$ Wald NJ, Boreham J, Bailey A. Relative intakes of tar, nicotine, and carbon monoxide from cigarettes of different yields. Thorax 1984; 39: 361-4.

${ }^{5}$ Feyerabend C, Russell MAH. Assay of nicotine in biological materials: sources of contamination and their elimination. J Pharm Pharmacol 1980; 32: 178-81.

${ }^{6}$ Feyerabend C, Russell MAH. A rapid gas-liquid chromatographic determination of cotinine in biological fluids. Analyst 1980; 105: 998-1001.

${ }^{7}$ Jarvis MJ, Russell MAH, Saloojee Y. Expired air carbon monoxide: a simple breath test of tobacco smoke intake. Br Med J 1980; 281: 484-5.

${ }^{8}$ Creighton DE, Lewis PH. The effect of smoking pattern on smoke deliveries. In: Thornton RE, ed. Smoking behaviour: physiological and psychological influences. London: Churchill Livingstone, 1978; 301-14.

${ }^{9}$ Stepney $\mathbf{R}$. Would a medium-nicotine, low-tar cigarette be less hazardous to health? Br Med J 1981; 283: 1292-6.

${ }^{10}$ Kozlowski LT, Rickert WS, Pope MA, Robinson JC, Frecker RC. Estimating the yield to smokers of tar, nicotine, and carbon monoxide from the "lowest yield", ventilated filter-cigarettes. $\mathrm{Br} J$ Addict 1982; 77: $159-65$.

${ }^{11}$ Hoffmann D, Adams JD, Haley NJ. Reported cigarette smoke values: a closer look. Am J Public Health 1983; 73: $1050-3$.

${ }^{12}$ Rawbone RG. Switching to low tar cigarettes: are the tar league tables relevant? Thorax 1984; 39: 657-62.

${ }^{13}$ Russell MAH. Are cigarettes getting safer? Br J Addict 1984; 79: 241-3. 